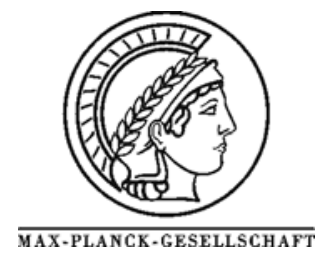

\title{
Bridging the pressure and materials gap: In-depth characterization and reaction studies of silver catalysed acrolein hydrogenation
}

\author{
M. Bron ${ }^{1}$, D. Teschner ${ }^{2}$, A. Knop-Gericke ${ }^{2}$, B. Steinhauer ${ }^{2}$, A. Scheybal ${ }^{2}$, M. Hävecker ${ }^{2}$, D. Wang ${ }^{2}$, \\ R. Födisch ${ }^{3}$, D. Hönicke ${ }^{3}$, A. Wootsch ${ }^{4}$, R. Schlögl ${ }^{2}$, P. Claus ${ }^{1 *}$ \\ ${ }^{1}$ Institute of Chemical Technology, Darmstadt University of Technology, Petersenstr. 20, \\ D-64287 Darmstadt, Germany \\ ${ }^{2}$ Fritz-Haber-Institut of the Max-Planck-Society, Department of Inorganic Chemistry, Faradayweg 4-6, \\ D-14195 Berlin, Germany \\ ${ }^{3}$ Chemnitz University of Technology, Str. d. Nationen 62, D-09111 Chemnitz, Germany \\ ${ }^{4}$ Institute of Isotopes, CRC, Hungarian Academy of Sciences, P. O. Box 77, Budapest, H-1525 Hungary \\ * Corresponding author: e-mail claus@,ct.chemie.tu-darmstadt.de, phone +49-6151-165369, fax +49-6151-164788

\begin{abstract}
The gas phase hydrogenation of acrolein over silver has been studied in a broad pressure range from $\sim 2$ mbar to 20 bar and with various silver materials (single crystals, sputtered silver, silica supported Ag nanoparticles) in an attempt to examine the question of "pressure and materials gap" in catalysis. High pressures as well as nanoparticles favour the formation of allyl alcohol (selectivities up to $42 \%$ ), whereas with the opposite conditions propionaldehyde is by far the main product. A critical minimum reaction pressure was identified: below ca. 100 mbar no allyl alcohol was formed. In situ-XAS measurements have been performed at 7.5 mbar in order to gain insight into the interaction of acrolein with silver samples. Despite the fact that beam-induced processes have been observed, it is concluded that at low pressures, acrolein orientates parallel to the surface on $\operatorname{Ag}(111)$ and is present at the surface in the form of hydrogenated propionaldehyde-like species. The influence of catalyst structure and pressure on the adsorption geometry of acrolein as well as the possible rate-determining step in acrolein hydrogenation are discussed.
\end{abstract}

Keywords: Acrolein; Silver; Selective Hydrogenation; Pressure Gap; Materials Gap; In situ-XAS

\section{Introduction}

The important question, whether results from catalysis research obtained under surface science conditions (i.e., ultra high vacuum, idealised surfaces like single crystals) are of relevance for industrial catalysis (i.e., high pressures, "real" catalysts) is currently attracting much interest within the catalysis community. For instance, "real" metal catalysts often consist of nanoparticles exhibiting edges, kinks and surface defects, and it is often suspected that defects as well as surface atoms on edges and kinks have a much stronger influence on the catalytic behaviour than the crystal planes of the nanoparticles. Many aspects of catalysis can therefore not be understood by simply performing experiments with different single crystals, even if open as well as closed single crystal planes are used. This so called "materials gap" points also to the problem of complexity, since industrial catalysts often consist of more than just the active component, and influences of e.g. an oxidic support for metal catalysts have also to be considered as well as the existence of different kinds of active sites. The "materials gap" is accompanied by a so called "pressure gap", expressing the problem that many important features in catalysis like adsorption/desorption, orientation of adsorbates, solubility of reactants in the active phase etc. and even the reaction mechanism may exhibit a strong pressure dependence. 
Hydrogenation on silver containing materials was reported mostly in relation with alloy (mainly Pd-Ag) catalysts $\left[{ }^{1},{ }^{2},{ }^{3}\right]$. In these systems silver decreases activity, but improves selectivity during hydrogenation in comparison with pure Pd catalysts. We are currently studying the hydrogenation of acrolein using pure silver catalysts $\left[{ }^{4}, 5\right]$ (with regard to the previously mentioned problem). The hydrogenation of acrolein (AC), an $\alpha, \beta$-unsaturated aldehyde, can proceed either to the saturated aldehyde, propionaldehyde (PA), or to the unsaturated alcohol, allyl alcohol (AyOH), as shown in Fig.1. From both products, the consecutive hydrogenation to n-propanol (n-PrOH) is possible as well as side reactions like decarbonylation or oligomerisation. When using silver catalyst, the selectivity to propanol or by-products is low (in most cases below 5 $\%$, and mainly allyl alcohol and propionaldehyde are formed. In this case, acrolein hydrogenation can be treated as a simple parallel reaction and is an ideal model system to study the effect of surface structure and reactant pressures on the intramolecular selectivity, i.e. the hydrogenation of $\mathrm{C}=\mathrm{C}$ vs. $\mathrm{C}=\mathrm{O}$ bond.

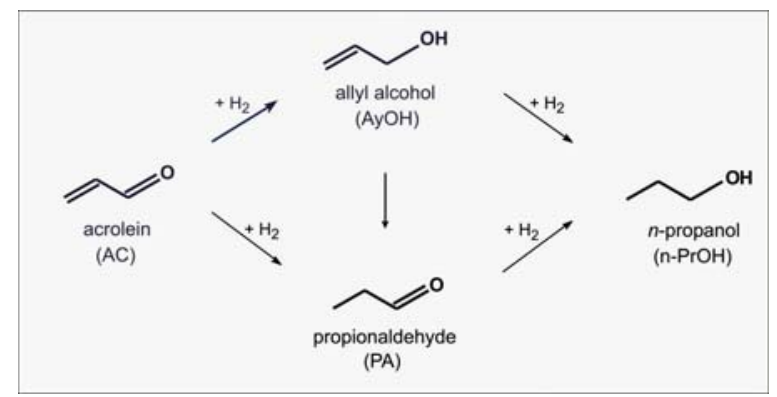

Figure 1: Reaction scheme of the acrolein hydrogenation

First ideas on the behaviour of the silver/acrolein system can be taken from the literature. Fuji et al. $\left[{ }^{6}\right]$ have studied the adsorption geometry of acrolein at evaporated silver films using infrared reflection absorption spectroscopy and $a b$ initio-calculations. They have found a coverage dependent adsorption geometry. Electropositive sites like kinks and edges favour the co-ordination of the $\mathrm{C}=\mathrm{O}$ double bond. Madix et al. showed, that electron deficient, Lewis-acid sites favour the coordination of the $\mathrm{C}=\mathrm{O}$-group, when oxygen is preadsorbed at $\operatorname{Ag}(110)\left[{ }^{7},{ }^{8}\right]$. Data for heats of adsorption are also available. Christmann reports a weak adsorption of hydrogen at $\operatorname{Ag}(110)$ with a value of 15 $\mathrm{kJ} / \mathrm{mol}\left[{ }^{9}\right]$. The adsorption of acrolein and allyl alcohol, on the other hand, is considerably stronger. Heats of adsorption of $59 \mathrm{~kJ} / \mathrm{mol}$ for acrolein and $71 \mathrm{~kJ} / \mathrm{mol}$ for allyl alcohol have been reported $\left[{ }^{10}\right]$. The high value for the heat of adsorption of allyl alcohol on silver is consistent with the findings of Khanra et al. $\left.{ }^{[1}\right]$. They have shown based on Bond-order conservation-Morse potential (BOC-MP) calculations, that allyl alcohol desorption exhibits the highest activation barrier in acrolein hydrogenation over $\operatorname{Ag}(111)$.

Our strategy to overcome the pressure and materials gap is to use materials ranging from single crystals to catalysts with nano-dispersed silver with a focus on systems with intermediate complexity (i.e., support-free silver material, flat substrates with sputtered or deposited silver) and to correlate activities and especially selectivities with the structural parameters of the catalysts. Experiments were performed in a broad pressure range ( 2 mbar -20 bar). We have recently shown, that under conditions relevant to industry (high pressures, supported Ag nanoparticles), the hydrogenation of $\mathrm{AC}$ indeed shows a pressure and material dependence [5].

\section{Experimental}

The different types of silver samples studied in the experiments are summarised in Table 1.

\subsection{Catalyst preparation}

The $\mathrm{Ag} / \mathrm{SiO}_{2}$ catalysts with a nominal metal loading of $9 \%$ have been prepared by incipient wetness (IW) or deposition-precipitation (DP) techniques. For the IW-catalyst, 20 $\mathrm{g}$ of silica gel (Alfa, "large pore", $\mathrm{d}_{\mathrm{p}}=15 \mathrm{~nm}$ ), $\mathrm{d}_{\text {particle }}=$ 0.2-0.5 mm, were dried under vacuum in an oven at $110{ }^{\circ} \mathrm{C}$ for $3 \mathrm{~h}$. After cooling down, $42 \mathrm{ml}$ of an aqueous solution containing $3.63 \mathrm{~g}$ of silver lactate (Fluka, "for histology") were added to the dried silica gel. The catalyst was then dried in a desiccator. For the DP-catalyst, $20 \mathrm{~g}$ of silica gel were suspended in $80 \mathrm{ml}$ of deionised water. A solution of $3.2 \mathrm{~g} \mathrm{AgNO}_{3}$ (Fluka, "reinst") in $50 \mathrm{ml} \mathrm{H}_{2} \mathrm{O}$ and a solution of $1.16 \mathrm{~g} \mathrm{NaOH}$ (Merck, p.A.) in $50 \mathrm{ml} \mathrm{H}_{2} \mathrm{O}$ were added to this suspension under vigorous stirring within one minute. Afterwards, the suspension was stirred for $3 \mathrm{~h}$ followed by filtering and thoroughly washing the filtrate. The catalyst

Table 1: Samples used in the investigations related to the materials gap, from more complex (top) to well defined (bottom)

\begin{tabular}{|c|c|c|}
\hline $\begin{array}{l}\text { nanoscopic sup- } \\
\text { ported silver }\end{array}$ & 9\% (nominal) $\mathrm{Ag}$ on $\mathrm{SiO}_{2}$ & $\begin{array}{c}\text { incipient wetness ("-IW"), } \\
\text { deposition-precipitation ("-DP") }\end{array}$ \\
\hline & $0.2 \mathrm{Ag} / \mathrm{SiO}_{2}-\mathrm{S}$ & Silver sputtered on $\mathrm{SiO}_{2}$ \\
\hline polycrystalline & $\mathrm{Ag} / \mathrm{Al}-\mathrm{S}$ & Silver sputtered on aluminium foil \\
\hline samples & $\mathrm{Ag} / \mathrm{Al}-\mathrm{E}$ & Silver electrolytically deposited on aluminium foil \\
\hline $\begin{array}{l}\text { single crystalline } \\
\text { samples }\end{array}$ & $\begin{array}{l}\text { polycrystalline silver foil } \\
\qquad \operatorname{Ag}(111), \operatorname{Ag}(100)\end{array}$ & \\
\hline
\end{tabular}


precursor was dried in a desiccator. The catalyst prepared via deposition-precipitation was calcined in flowing air at $250{ }^{\circ} \mathrm{C}$ for $2 \mathrm{~h}$ and reduced in flowing hydrogen at $325^{\circ} \mathrm{C}$ for $2 \mathrm{~h}$, the IW-catalyst was reduced at $325^{\circ} \mathrm{C}$ for $2 \mathrm{~h}$ only. The real metal loading, determined by ICP-OES, was $8.1 \%$ for the DP catalyst and $7.5 \%$ for the IW catalyst. They are labelled as $8.1 \mathrm{Ag} / \mathrm{SiO}_{2}-\mathrm{DP}(\mathrm{NaOH})$ and $7.5 \mathrm{Ag} / \mathrm{SiO}_{2}-\mathrm{IW}$, respectively.

\section{Silver sputtered on aluminium foil ("Ag/Al-S")}

The support material Al-99.5 (aluminium foil, $4 \times 4$ $\mathrm{mm}$ ) was degreased using tetrachlorethylene followed by a pickling of the material by placing it in $10 \%$ sodium hydroxide and afterwards $10 \%$ nitric acid 10 seconds each time. Finally the support material was washed using distilled water and dried. Silver coating was done using a SC 7640 sputter coater and a silver target Ag 99.95 by Chempur. Sputtering parameters were: $U=1.6 \mathrm{kV} ; \mathrm{p}=3 \mathrm{~Pa}$; $\mathrm{I}=25$ $\mathrm{mA}$. The thickness of the Ag layer obtained in this way was about $100 \mathrm{~nm}$. Additionally, a catalyst with silver sputtered on silica gel (metal loading ca. $0.2 \%$ ) was also prepared, labelled $0.2 \mathrm{Ag} / \mathrm{SiO}_{2}-\mathrm{S}$.

\section{Electrochemically deposited silver ("Ag/Al-E")}

The starting material was the catalyst Ag/Al-S. At a temperature of $288 \mathrm{~K}$ the samples were placed in an electrolyte solution having the following composition: $7.5 \mathrm{~g}$ $\mathrm{AgNO}_{3}$ and $37.5 \mathrm{~g} \mathrm{NH}_{4} \mathrm{SCN}$ in $250 \mathrm{ml}$ distilled water. The counter electrode was a silver plate at a distance of $3 \mathrm{~cm}$. For electrochemical surface smoothing the samples were operated as anodes at a voltage of $1 \mathrm{~V}$ for 10 seconds. Silver deposition was done cathodically at a current density of $0.4 \mathrm{~A} / \mathrm{dm}^{2}$ for 2 hours. The thickness of the silver layer obtained in this way was $100 \mu \mathrm{m}$.

\section{Bulk silver}

Silver single crystals and foil were used in the in situ-XAS measurements (see later, sect. 2.4). Additionally, they were catalytically tested in the medium pressure range (50-1000 mbar), however in this pressure range no measurable conversion was detected.

\subsection{Catalysis}

Catalytic experiments were performed in the pressure region of $2.6 \mathrm{mbar}$ to $20 \mathrm{bar}$. In the range of $350 \mathrm{mbar}$ to 20 bar, experiments were performed in continuous gas flow reaction systems with a gas chromatograph as analytical system. In the case of $\mathrm{Ag} / \mathrm{SiO}_{2}$ catalysts, $50-250 \mathrm{mg}$ have been used, depending on the activity. The catalysts have been reduced in situ at $250{ }^{\circ} \mathrm{C}$ before each experiment in pure hydrogen. Mass flow controllers were used for gas dosing; acrolein was dosed by a liquid flow controller and evaporated afterwards. Two different systems have been used for the continuous flow experiments, one for the region of 350-950 mbar and another one for 5 to 20 bar [ [2]. The reaction temperature was $250{ }^{\circ} \mathrm{C}$, except for the determination of activation energy values, where temperatures from $200 \ldots .300{ }^{\circ} \mathrm{C}$ have been used. The $\mathrm{H}_{2} /$ acrolein ratio was $20: 1$ with a $\mathrm{H}_{2}$ flow rate of $6.7 \mathrm{l} / \mathrm{h}$.

Catalytic experiments were also carried out in a closed-loop reactor system $\left[{ }^{13}\right]$ in the pressure range between 2.6 to 790 mbar. Products were analyzed using a gas chromatograph equipped with a FID detector and a $30 \mathrm{~m}$ WAX glass capillary column. The hydrogen to acrolein ratio and the temperature was identical to the continuous flow experiments.

The experiments during the in situ-XAS measurements have been performed in batch-mode at 7.5 mbar; product analysis has been carried out via MS (see below for details).

\subsection{Catalyst characterisation}

The characterisation of the catalysts has been performed by X-ray photoelectron Spectroscopy (XPS), Auger electron spectroscopy (AES), Transmission electron microscopy (TEM), and X-ray Diffraction (XRD).

Details of electron spectroscopy have been reported earlier $\left[{ }^{14}\right]$. A Leybold LHS 12 MCD instrument was used, and the measurements were performed with a pass energy (PE) of $\mathrm{PE}=48 \mathrm{eV}$. The binding energy (BE) was calibrated to the $\mathrm{Au} 4 \mathrm{f} 7 / 2$ line $(\mathrm{BE}=84.0 \mathrm{eV})$. Atomic composition was calculated assuming homogeneous distribution of the various elements in the information depth. The samples were treated in $\mathrm{H}_{2}$ at $325{ }^{\circ} \mathrm{C}$ in the preparation chamber of the XPS set-up, and then transferred to the analysis chamber without contact to air.

\subsection{In situ-X-ray absorption spectroscopy under reaction conditions}

XAS (X-ray absorption spectroscopy) experiments were performed in a special reactor cell at the undulator beamline U/49-2 at BESSY in Berlin, Germany. Details about the set-up and the data processing can be found in the literature $\left[{ }^{1} 5,{ }^{16}\right]$. Briefly, the set-up consists of two chambers. One (pumping stage) is attached to the beamline, whereas the catalytic reaction proceeds in the second chamber (reaction cell), which is separated from the first chamber by a $200 \mathrm{~nm}$ thick $\mathrm{SiN}_{\mathrm{x}}$-window. The catalyst is mounted on a heating stage, which can be aligned with respect to the X-ray beam by means of a manipulator. The distance between the sample and the $\mathrm{SiN}_{\mathrm{x}}$-window is about $15 \mathrm{~mm}$. The gas feed is provided by a mass flow controller (hydrogen) and a leak valve. Acrolein was cleaned by three freeze/pump and thaw cycles. The detector of the surface 
Table 2: XPS/Auger data of selected Ag catalysts. All catalysts have been reduced in situ at $325^{\circ} \mathrm{C}$ except where indicated

\begin{tabular}{|c|c|c|c|}
\hline Catalysts & $\operatorname{Ag} 3 d_{5 / 2}$ & $\mathrm{Ag} \mathrm{M}_{4} \mathrm{~N}_{45} \mathrm{~N}_{45}$ & $\begin{array}{c}\text { Auger parameter } \\
\left(\alpha^{\prime}\right)\end{array}$ \\
\hline $8.1 \mathrm{Ag} / \mathrm{SiO}_{2}-\mathrm{DP}(\mathrm{NaOH})$ (unreduced) & 372.85 & 351.5 & 724.35 \\
\hline $8.1 \mathrm{Ag} / \mathrm{SiO}_{2}-\mathrm{DP}(\mathrm{NaOH})$ & 373.35 & 352.4 & 725.75 \\
\hline $0.2 \mathrm{Ag} / \mathrm{SiO}_{2}-\mathrm{S}$ & 372.95 & 352.8 & 725.75 \\
\hline $7.5 \mathrm{Ag} / \mathrm{SiO}_{2}-\mathrm{IW}$ & 373.1 & 352.85 & 725.95 \\
\hline
\end{tabular}

related signal consists of an aluminium "collector" plate, which is located between the X-ray window and the sample provided with a hole in the centre for the photons. A voltage of $27 \mathrm{~V}$ is applied on the plate to collect all electrons. The gas phase detector consists of a cylinder, which is located between the X-ray window and the $\mathrm{Al}$ plate to detect the absorption signal of the gas phase. Carbon K-edge gas phase and collector plate (surface related plus gas phase) signal were recorded in the total electron yield mode (TEY) in situ. The absolute energy was calibrated by measuring the oxygen gas-phase $\pi^{*}$ transition at $530.8 \mathrm{eV}$. The reactor cell was operated in batch mode with a gas mixture of 0.01

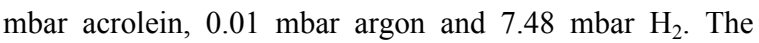
reaction was monitored by online mass spectrometer (MS). The quantification of conversion and reaction selectivities was achieved by calibration of selected $\mathrm{m} / \mathrm{e}$ signals. The MS signals cannot be correlated to only one reaction product because of the same molecule mass (AyOH, PA), and/or the fragmentation by the ionisation process via electron impact in the MS. However, characteristic amu's were 56 for $\mathrm{AC}, 57$ for $\mathrm{AyOH}, 58$ for $\mathrm{PA}$ and 59 for $\mathrm{n}-\mathrm{PrOH}$. Conversion was calculated from the increase of product masses and not from the decrease of amu "56". The gas phase XAS spectra of the hydrogenation products of acrolein have been measured in order to follow the reaction also via XAS and to be able to better assign the XAS features of acrolein.

In situ-XAS measurements were carried out on silver single-crystals ( $\operatorname{Ag}(111), \operatorname{Ag}(100))$, polycrystalline $\mathrm{Ag}$ foil and supported catalyst $\left(7.5 \mathrm{Ag} / \mathrm{SiO}_{2}-\mathrm{IW}\right)$. The angle of incident beam to sample surface was varied on single crystals $\left(90^{\circ}\right.$ : normal incidence, $30^{\circ}$ : grazing incidence). The supported sample was immobilised on $\mathrm{Al}$ foil using $\mathrm{SiO}_{2}$. The samples were cleaned using oxygen (flowing $\mathrm{O}_{2}, 0.07$ mbar, $250{ }^{\circ} \mathrm{C}$ ) and hydrogen (flowing $\mathrm{H}_{2}, 0.1$ mbar, 120 ${ }^{\circ} \mathrm{C}$ ) treatments prior to the measurements.

\section{Results}

\subsection{Catalyst characterisation}

The characterisation of the catalysts was performed with different methods, depending on the type of catalyst. Disperse catalysts were investigated with TEM and XPS, catalysts sputtered on flat substrates have been characterised with XRD and XPS

\subsubsection{XPS}

Silica supported Ag nanoparticles have been characterised with XPS (Fig. 2). The samples - as usual with insulator supports - are charged by 5-6 eV. The charging was corrected as the binding energy of Si $2 p$ was set at 103.4 $\mathrm{eV}$, characteristic for $\mathrm{SiO}_{2}$. In this way, the $\mathrm{O} 1 \mathrm{~s}$ peaks (not shown) are found at $532.8 \mathrm{eV}$, in good agreement with literature data. $\mathrm{O} / \mathrm{Si}$ ratios of 2.1-2.2 were observed. (The ratio measured for the pure support was 2.15.) Sodium was found in the samples prepared by precipitation $(\mathrm{Na} / \mathrm{Si}$ between 0.01-0.04).
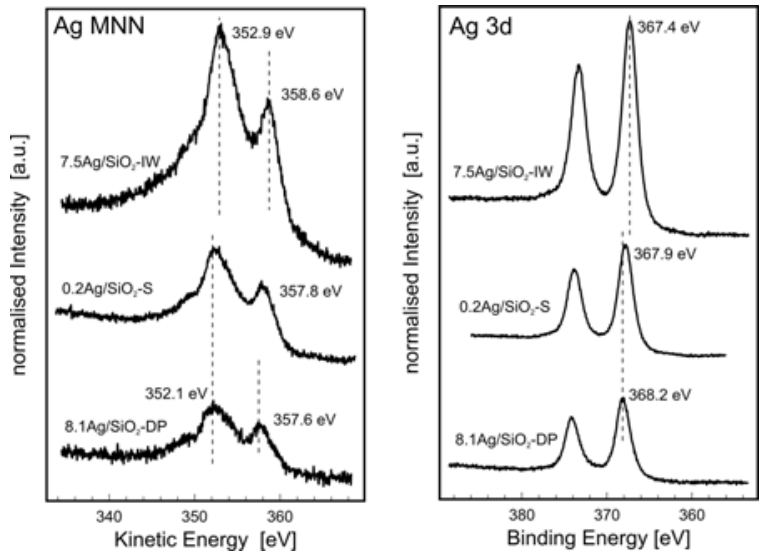

Figure 2: XPS Ag 3d and Ag MNN spectra of different $\mathrm{Ag} / \mathrm{SiO}_{2}$ catalysts. See text for details.

A series of Ag 3d and Ag MNN Auger (energy corrected) spectra on selected catalysts are shown in Fig. 2. The energy positions do not identify unambiguously the oxidation state of the silver, some of the $3 \mathrm{~d}$ peaks are shifted towards low binding energies. (Binding energy of metallic $\mathrm{Ag}$ was found to be $368.1 \mathrm{eV}$ and that of $\mathrm{Ag}_{2} \mathrm{O}$ $367.7 \mathrm{eV}$. $\left.\left[{ }^{17}\right]\right)$ To identify the oxidation state the modified Auger parameter $\left(\alpha^{\prime}\right)$ was calculated $\left[{ }^{18}\right]$, which is the sum of the kinetic energy of the Auger electron $\left(\mathrm{Ag} \mathrm{M}_{4} \mathrm{~N}_{45} \mathrm{~N}_{45}\right)$ and the binding energy of the core level $\left(\mathrm{Ag} 3 \mathrm{~d}_{5 / 2}\right)$ peak. As this parameter is known to be independent of charging, but also sensitive to chemical shifts it was calculated for the different samples (Table 2). The modified Auger parameter demonstrates that $\mathrm{Ag}$ in the prereduced samples is in form of $\operatorname{Ag}(0)$. An additional experiment on the sample prepared by precipitation without $\mathrm{H}_{2}$ treatment after calcinations shows $\mathrm{Ag}_{2} \mathrm{O}$. Auger parameters are for $\mathrm{Ag}(0) 726.1 \mathrm{eV}$ and for $\mathrm{Ag}_{2} \mathrm{O} 724.4 \mathrm{eV}$ [17]. The apparent low binding energies 
(shown in Fig. 2) were caused, therefore, by differential charging (with respect to $\mathrm{SiO}_{2}$ ).

\subsection{2. $X R D$}

The surface structure of the Ag/Al-S and Ag/Al-E catalysts was examined using X-ray diffraction. Reflexes at 38.0 and $44.12 \theta$ can be found (not shown), indicating that silver is present in the samples prepared by sputtering and electrochemical deposition in crystalline form.

\subsubsection{TEM}

(HR)TEM images of three different $\mathrm{Ag} / \mathrm{SiO}_{2}$ catalysts are presented in Fig. 3. Very small particles with a mean particle size of about 2-3 nm (see particle size distribution inset Fig. 3a) have been found for the catalyst prepared via incipient wetness method, $7.5 \mathrm{Ag} / \mathrm{SiO}_{2}-\mathrm{IW}$, as seen in Fig. 3a. The very small particles are indicated by the white circles. One much bigger particle is also included with diameter of $\sim 12 \mathrm{~nm}$. Its power spectrum does not match the single crystalline face centered cubic (fcc) $\mathrm{Ag}$ structure. However, it could be explained by a single twinned particle, with the twinned parts overlapping with each other. Fig. $3 \mathrm{~b}$ shows the catalyst $8.1 \mathrm{Ag} / \mathrm{SiO}_{2}-$ $\mathrm{DP}(\mathrm{NaOH})$. Larger particles can be found with a mean particle diameter of $c a .15 \mathrm{~nm}$ (inset Fig. 3b). The HRTEM image cannot be simply determined as single crystalline fcc structure or a twinned particle. There possibly exists phases other than the fcc Ag (silicide?). The possibility of hexagonal Ag particle with [021] orientation cannot be ruled out. Interestingly, the adhesion of the particles to the support is low, so that a large number of the silver particles can be found on the TEM grid instead of the support. The largest Ag particles are observed on the sputtered catalyst $0.2 \mathrm{Ag} / \mathrm{SiO}_{2}-\mathrm{S}$ (Fig. 3c), where particles in the range of 20 $30 \mathrm{~nm}$ as well as up to $200 \mathrm{~nm}$ can be found.

\subsection{Catalysis}

Recently we have shown that the selectivity to allyl alcohol during acrolein hydrogenation over silver depends on the partial pressures of acrolein and hydrogen in the industrially relevant pressure region of 5-20 bar [5]. Additionally, a dependence on the reaction pressure has been found down to 7.5 mbar [19]. We have now investigated this pressure dependence in much more detail, especially in the low-pressure region. Fig. 4 shows the selectivity to allyl
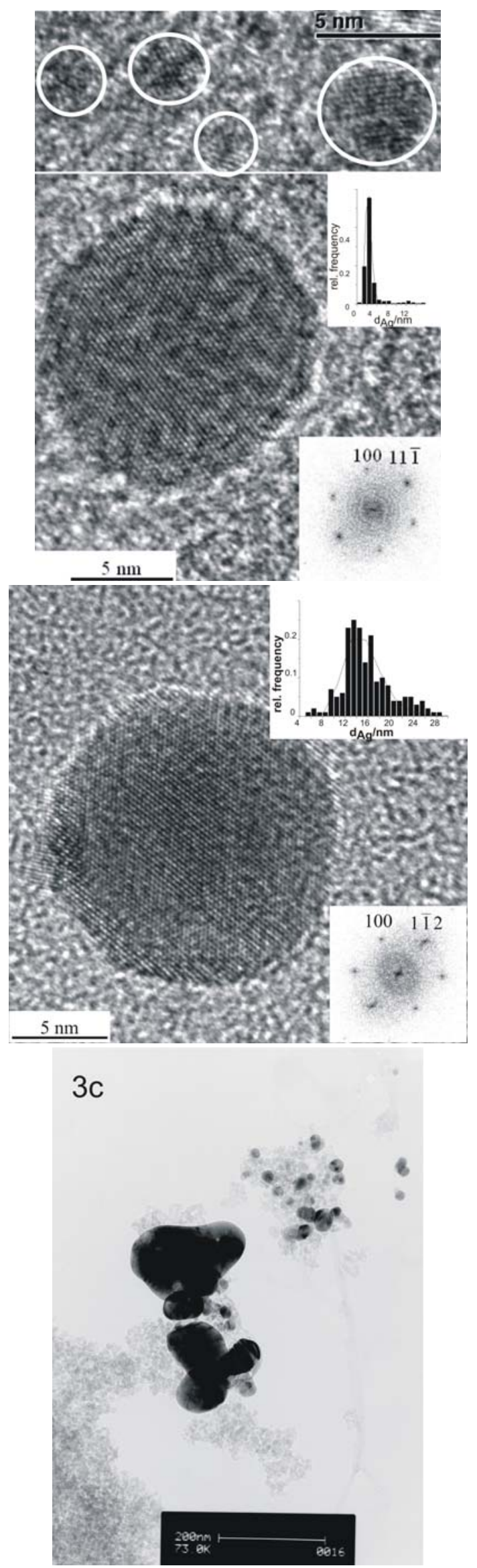

Figure 3: TEM images of three different $\mathrm{Ag} / \mathrm{SiO} 2$ catalysts: a) $7.5 \mathrm{Ag} / \mathrm{SiO}_{2}-\mathrm{IW}$, b) $8.1 \mathrm{Ag} / \mathrm{SiO}_{2}-\mathrm{DP}$, c) $0.2 \mathrm{Ag} / \mathrm{SiO}_{2}$ $\mathrm{S}$. 
alcohol in the acrolein hydrogenation in a pressure range over four order of magnitudes ( $\sim 2$ mbar....20 bar) on the $7.5 \mathrm{Ag} / \mathrm{SiO}_{2}$-IW catalyst. The different symbols represent results originating from four different catalytic setups, which were used to cover the whole pressure range. A strong dependence of the selectivity towards allyl alcohol on the reaction pressure has been found above a certain pressure. From $\sim 100$ mbar reaction pressure allyl alcohol formation strongly increases, while at higher pressures the selectivity increase slows down. Note that the closed-loop batch experiments gave a quite good agreement with the data from the continuous flow measurements. At and below 75 mbar, using 20:1 reaction mixture, no allyl alcohol was produced. This latter result indicates that the hydrogenation of the $\mathrm{C}=\mathrm{O}$ bond of acrolein does not proceed until a certain coverage level of the silver surface is reached. It is also possible that some restructuring of the catalyst has to occur that cannot take place below $\sim 100$ mbar. Indeed, in recent experiments we have found that sintering of silver particles occurs at low pressures under reaction conditions, which is not observed at higher pressures (20 bar-region) [20].

At 7.5 mbar XAS experiments under reaction conditions were performed on $\mathrm{Ag}(111), \operatorname{Ag}(100)$, polycrystalline $\mathrm{Ag}$ foil and $7.5 \mathrm{Ag} / \mathrm{SiO}_{2}$-IW. Unexpectedly, all the silver samples (also the single crystals) showed catalytic activity during the in situ-XAS experiments, measurable with MS, even at room temperature. A clear increase of signals amu " 58 " and " 57 " was observed, however that of " 58 " was much more dominant. The ratio of the " 58 " to " 57 " slopes was usually $\sim 3.3 \pm 0.2$. Calibration of the MS with propionaldehyde gave a $\mathrm{I}_{58} / \mathrm{I}_{57}$ ration of 3.2 , thus the reaction proceeds exclusively towards PA formation. Allyl alcohol was not produced in good agreement with the selectivity plot shown in Figure 4.

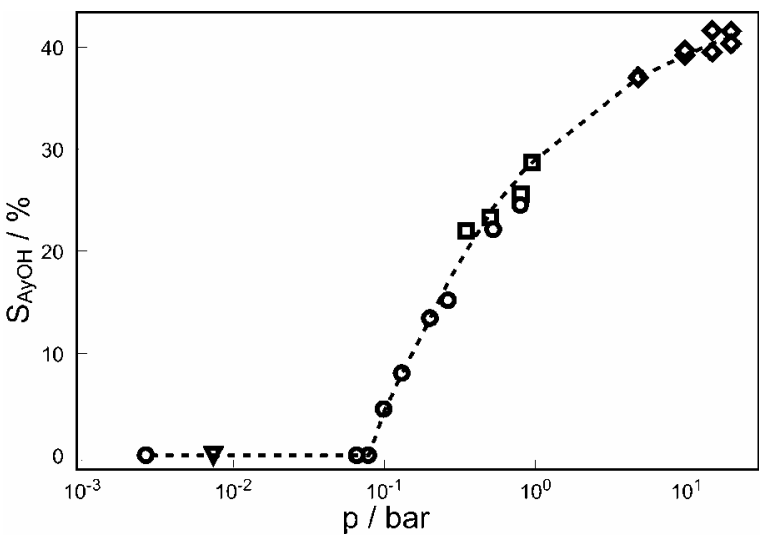

Figure 4: Pressure dependence of the selectivity towards allyl alcohol formation in the gas phase hydrogenation of acrolein over $7.5 \mathrm{Ag} / \mathrm{SiO}_{2}-\mathrm{IW}$. Reaction temperature $250{ }^{\circ} \mathrm{C}$ (except for 7.5 mbar; RT). Different symbols represent results originating from different experimental setups. $\nabla:$ in situ-XAS at 7.5 mbar; O: closed-loop batch experiments; $\diamond$ and : flow experiments

The calculated conversions during one hour of experimentation time were about 1-5 \%, showing therefore surprisingly low sensitivity to the kind of silver samples used. Taking into account the amount of $7.5 \mathrm{Ag} / \mathrm{SiO}_{2}-\mathrm{IW}$ used for the in situ-XAS measurements and its approximate silver dispersion $(40 \%)$, the calculated number of surface $\mathrm{Ag}$ atoms are 3 orders of magnitude higher than for single crystals or for Ag foil. This and the fact that reaction occurs even at room temperature points to a beam induced effect on the illuminated surface. At "normal" reaction temperature $\left(250{ }^{\circ} \mathrm{C}\right)$ the reaction proceeds instead of hydrogenation towards decarbonylation. This was evidenced by both the MS pattern and by the characteristic gas phase XAS signal of CO and ethane (not shown). Note, that thermal activation at $280 \ldots 480 \mathrm{~K}$ of acrolein adsorbed on $\operatorname{Pt}(111)$ leads to decarbonylation (to carbon monoxide and ethene) and traces of ketene and propene [21].

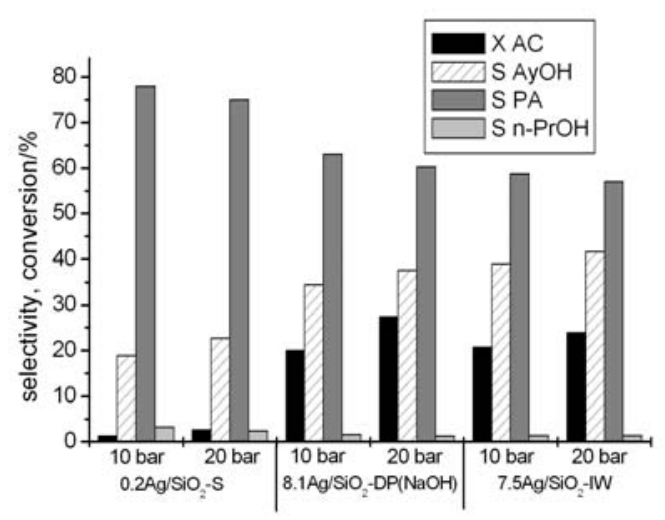

Figure 5: Conversion and selectivity to the main products in the gas phase hydrogenation of acrolein over various $\mathrm{Ag} / \mathrm{SiO}_{2}$-catalysts in the high pressure range. Reaction temperature $250{ }^{\circ} \mathrm{C}$.

Besides the pressure dependence, the selectivities depend also on the silver material used. In the highpressure range ( 5 to 20 bar), investigations have focussed on differently prepared $\mathrm{Ag} / \mathrm{SiO}_{2}$-catalysts. Different selectivities to allyl alcohol, depending on the preparation procedure (i.e., the structural features of the catalyst) have been found, as summarised in Fig. 5. Selectivities up to 42 $\%$ to allyl alcohol have been obtained over the catalyst prepared via incipient wetness. The maximum selectivity obtained over $8.1 \mathrm{Ag} / \mathrm{SiO}_{2}-\mathrm{DP}(\mathrm{NaOH})$ was $39 \%$. Much lower values (about $23 \%$ ) have been found with the sputtered catalyst $0.2 \mathrm{Ag} / \mathrm{SiO}_{2}-\mathrm{S}$. Note that the selectivities have been obtained at different degrees of conversion. However, the influence of conversion on selectivity is low, as proven in a number of experiments [5]. In the medium pressure range (100 to 1000 mbar), additionally sputtered or electrochemically deposited silver catalysts deposited on flat substrates have been investigated. The selectivity of different products are summarised in Fig. 6. With sputtered silver (layer thickness $100 \mathrm{~nm}$ ), 8-10\% allyl alcohol has been obtained. When silver is sputtered onto the support material $\mathrm{SiO}_{2}$ (catalyst $0.2 \mathrm{Ag} / \mathrm{SiO}_{2}-\mathrm{S}$ ), selectivities to allyl alcohol of up to $12 \%$ have been obtained at these pressures. It should be pointed out that over silica supported $\mathrm{Ag}$ nanoparticles much higher selectivities to allyl alcohol have 
Table 3; Activation energy values of acrolein hydrogenation over two different silver catalysts, determined by the Arrhenius equation. $\mathrm{T}_{\mathrm{R}}=200-300^{\circ} \mathrm{C}$.

\begin{tabular}{ccccc}
\hline catalyst & pressure & $\begin{array}{c}\mathrm{E}_{\mathrm{A}}\left[\mathrm{kJ} \mathrm{mol}^{-1}\right] \\
(\mathrm{AC}-\text {-consumption })\end{array}$ & $\begin{array}{c}\mathrm{E}_{\mathrm{A}}\left[\mathrm{kJ} \mathrm{mol}^{-1}\right] \\
(\mathrm{PA}-\text {-formation) }\end{array}$ & $\begin{array}{c}\mathrm{E}_{\mathrm{A}}\left[\mathrm{kJ} \mathrm{mol}^{-1}\right] \\
\text { (AyOH-formation) }\end{array}$ \\
\hline $7.5 \mathrm{Ag} / \mathrm{SiO}_{2}-\mathrm{IW}$ & $0.98 \mathrm{bar}$ & 37 & 40 & 32 \\
$7.5 \mathrm{Ag} / \mathrm{SiO}_{2}-\mathrm{IW}$ & $5 \mathrm{bar}$ & 38 & & 35 \\
$8.1 \mathrm{Ag} / \mathrm{SiO}_{2}-\mathrm{DP}(\mathrm{NaOH})$ & $0.98 \mathrm{bar}$ & 36 & 43 & 36 \\
$8.1 \mathrm{Ag} / \mathrm{SiO}_{2}-\mathrm{DP}(\mathrm{NaOH})$ & $5 \mathrm{bar}$ & 41 & 41 & 35 \\
$8.1 \mathrm{Ag} / \mathrm{SiO}_{2}-\mathrm{DP}(\mathrm{NaOH})$ & $15 \mathrm{bar}$ & 39 & & \\
\hline
\end{tabular}

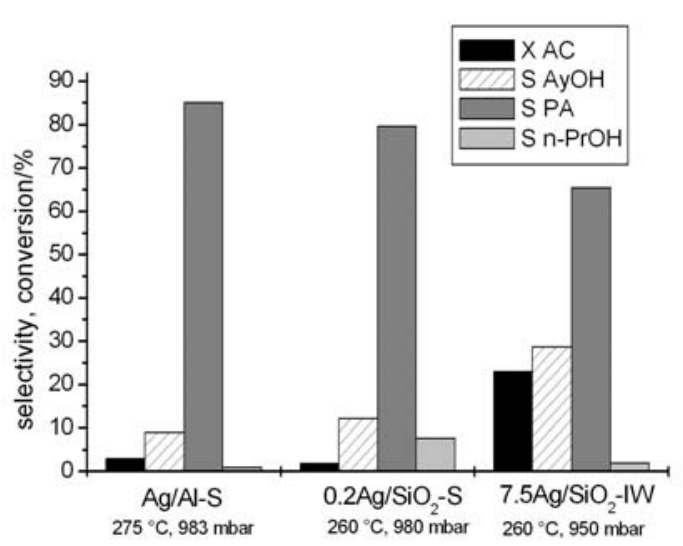

Figure 6: Conversion and selectivity to the main products in the gas phase hydrogenation of acrolein over various $\mathrm{Ag}$ catalysts in the medium pressure range.

been observed (see also above). On the other hand, electrochemically deposited catalysts (thickness of catalyst layer: $100 \mu \mathrm{m}$ ) yielded mainly propionaldehyde as product. Due to the uncertainty in the determination of the exact selectivity values (due to low conversion), the data have not been included in Fig. 6.

Additionally, attempts have been made to use single crystals or electrolytic silver as catalysts in the hydrogenation of acrolein in medium pressure range. Over these samples, no conversion has been observed. However, this can be due to the low surface area of these samples resulting in conversions below the limits of detection in the system.

Although there is a pressure dependence of the selectivities in the gas phase hydrogenation of acrolein, no dependence of activation energy on the reaction pressure or the catalyst material can be found. (Note that activation energy was calculated only for the two well dispersed $\mathrm{Ag} / \mathrm{SiO}_{2}$ samples.) Values for the activation energies, both for acrolein consumption and for the formation of the main products, are summarised in Table 3 . The only characteristic difference in the $E_{a}$ values is that the activation energy for allyl alcohol formation is slightly lower (by ca. 5-8 $\mathrm{kJ} / \mathrm{mol}$ ) than that of propionaldehyde formation.

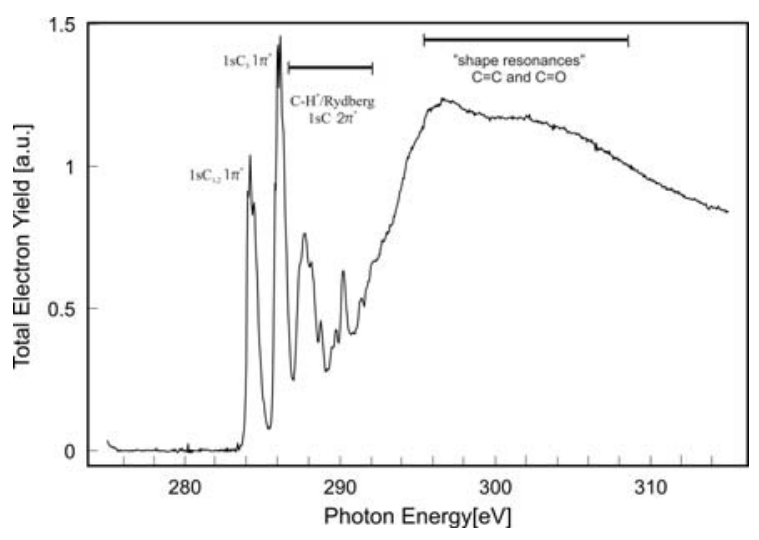

Figure 7: Gas phase spectrum of acrolein at the carbon Kedge.

\subsection{In situ-XAS under reaction conditions}

The gas phase X-ray absorption spectrum of acrolein at the $\mathrm{C}$ 1s edge is shown in Fig. 7. The most interesting 283-291 eV region is displayed also in Fig. 10 (the shaded area) after background subtraction. (A quasi-continuous background subtraction has been used in Fig. 9 and 10 to allow a better comparison of the resonant features.) The spectrum is generally similar to the gas phase ISEELS [22] and condensed phase NEXAFS [23] spectra of acrolein but reveals also some differences and new details due to the better resolution. The spectrum is dominated by the first two intense resonances, centered at 284.2 and $286.1 \mathrm{eV}$, corresponding to the $1 \mathrm{sC}_{1,2} 1 \pi^{*}$ and $1 \mathrm{sC}_{3} 1 \pi^{*}$ transitions, respectively. (According to the "building block" model, these are transitions from the $1 \mathrm{~s}$ core shell to the first $\pi^{*}$ antibonding orbital, respectively to the first/second $(\mathrm{C}=\mathrm{C})$ or to the third $(\mathrm{C}=\mathrm{O})$ carbon atom. $)$ The fine structure seen in these two bands are vibrational excitations [24]. Comparison with gas phase spectra of potential hydrogenation products of acrolein reveals that the $287.3 \mathrm{eV}$ shoulder in the third peak was always present. Consequently, we assign this to a $\sigma^{*} \mathrm{C}-\mathrm{H}$ and/or $3 \mathrm{~s}$ Rydberg excitation of $\mathrm{C}_{1,2}$. The next maximum, located at $287.7 \mathrm{eV}$, was explained by the $1 \mathrm{sC}_{2} 2 \pi^{*}$ transition. The final state of this second $\pi^{*}$ transition corresponds to LUMO+1 and appears with conjugated $\pi$ systems. The assignment seems to be correct as the transition was absent with propionaldehyde (see Fig. 8 spectrum 4: the minimum position between the $2^{\text {nd }}$ and $3^{\text {rd }}$ 
peak). The shoulder at $288.2 \mathrm{eV}$ is the typical counterpart [25] of the $287.3 \mathrm{eV}$ component corresponding to the $\sigma^{*} \mathrm{C}$ $\mathrm{H}$ of $\mathrm{C}_{1,2}$. The fine structure in the $288-289 \mathrm{eV}$ range was explained by excitations to $1 \mathrm{sC}_{3} 2 \pi^{*}(288.7 \mathrm{eV})$ and to Rydberg states. The peak at $290.2 \mathrm{eV}$ (and its pre-peak at $\sim 289.5 \mathrm{eV})$ can be correlated to the $1 \mathrm{sC}_{3} 3 \mathrm{~s} / \sigma^{*}(\mathrm{C}-\mathrm{H})$ transitions, considering the core ionisation energy shift of $\mathrm{C}_{3}$ $[22,26]$ and the observed energy separation of $C_{1,2} / C_{3} 1 \pi^{*}$. The presence and position of this structure in propionaldehyde strengthen our assignment. The last two diffuse bands, at about 297 and $303 \mathrm{eV}$, are $\sigma^{*}$ "shape resonances" of $\mathrm{C}=\mathrm{C}$ and $\mathrm{C}=\mathrm{O}$.

Silver single-crystals $(\operatorname{Ag}(111), \operatorname{Ag}(100))$, polycrystalline $\mathrm{Ag}$ foil and supported catalyst $\left(7.5 \mathrm{Ag} / \mathrm{SiO}_{2}-\mathrm{IW}\right)$ were used to learn about the interaction of acrolein with silver and about the orientation of acrolein on well-oriented surfaces in the presence of reaction mixture $(0.01 \mathrm{mbar}$ AC $+7.48 \mathrm{mbar}_{2}$ ) (see Ref. [19] for preliminary results on the $\mathrm{Ag}(111)$ phase). Using XAS gas-phase detection (see 2.4), the gas-phase composition has been checked with XAS during the in situ-experiments. Gas phase original spectra (after introducing reaction mixture and one hour later) using $\operatorname{Ag}(100)$ as catalyst are shown together with their difference spectrum in Fig 8. The calculated conversion was $\sim 5 \%$ during this one hour. The gas phase spectrum of propionaldehyde and allyl alcohol (spectra 4 and 5) demonstrate that the reaction goes entirely in the direction of $\mathrm{C}=\mathrm{C}$ saturation, in agreement with the results of the product analysis via MS (see above).

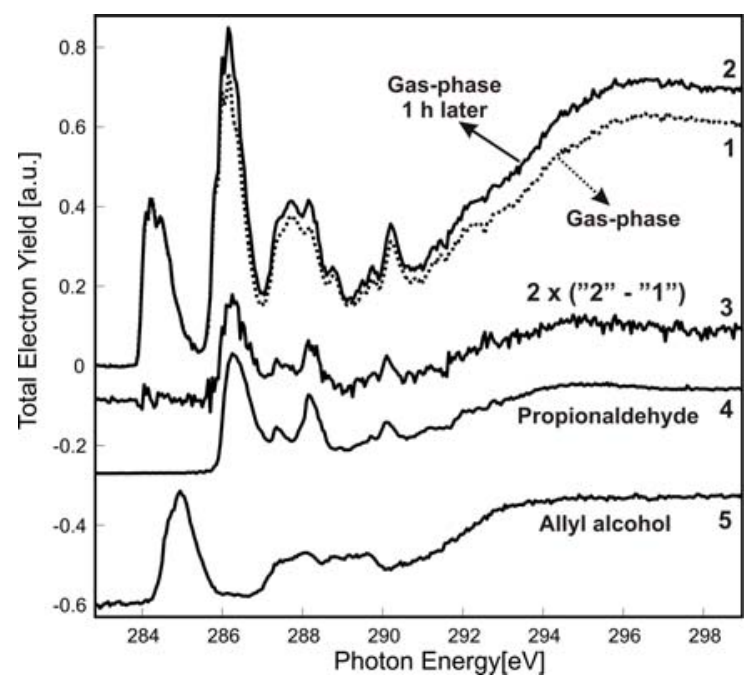

Figure 8: Gas phase C K-edge spectra (1 and 2) measured on $\operatorname{Ag}(100)$ in the hydrogenation of acrolein. 1 measured right after introducing reaction mixture and 2 one hour later. The difference spectrum (3) was calculated as $2 x($ spectrum 2 - spectrum 1 ), thus the difference is representative for the catalytic action during this one hour. Gasphase spectrum of propionaldehyde (4) and allyl alcohol (5) is also shown for a comparison.

To obtain information about the chemisorption geometry of acrolein during catalytic runs, angular dependent measurements on silver single crystals were applied. C K-

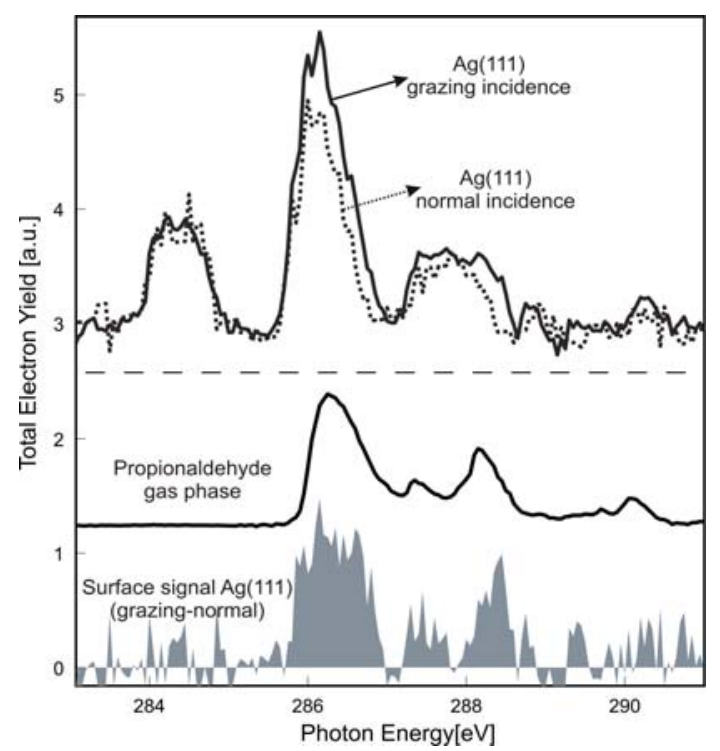

Figure 9: Part of the collector plate spectra (surface related plus gas-phase signal) on $\mathrm{Ag}(111)$ at two incidence angle (normal: $90^{\circ}$; grazing: $30^{\circ}$ ) after background subtraction. At the bottom, difference spectrum of "grazing" - "normal" incidence spectrum (shown here as shaded area). As a comparison gas-phase spectrum of propionaldehyde is also shown (The Fig. 8 spectrum after background subtraction).

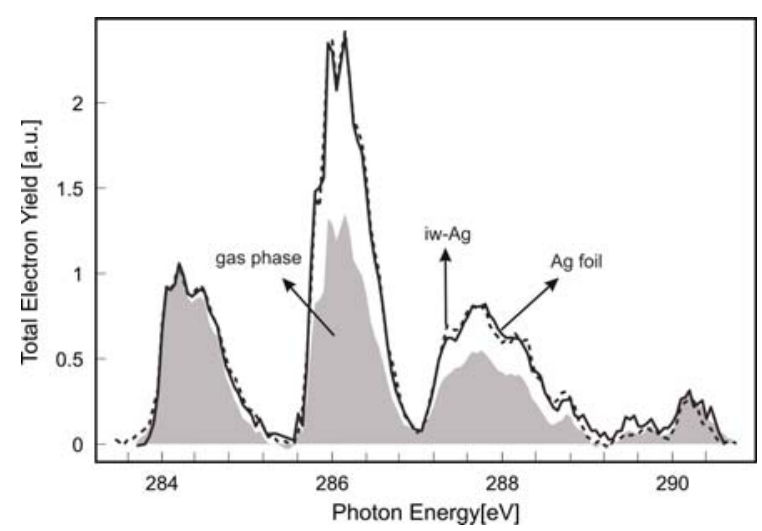

Figure 10: Part of the collector plate spectra (surface related plus gas-phase signal) on $\mathrm{Ag}$ foil and $7.5 \mathrm{Ag} / \mathrm{SiO}_{2}-\mathrm{IW}$ after background subtraction. The same region of the gasphase spectrum from Fig. 7 is displayed as shaded spectrum after similar background subtraction.

shell collector plate (gas phase plus surface related signal) spectra of acrolein on $\mathrm{Ag}(111)$ recorded at grazing ( $\boldsymbol{E}$ vector $30^{\circ}$ from surface normal) and normal X-ray incidence ( $\boldsymbol{E}$ vector in the surface plane) are shown in Fig. 9. (There was no difference between the corresponding gas phase spectra, not shown separately, while measured at two incidence angles, thus the conversion between the two scans was lower than detectable by XAS.) At grazing incidence the intensity of the $1 \mathrm{sC}_{3} 1 \pi^{*}$ transition and those in the third peak (except at about $287.7 \mathrm{eV}$ ) are enhanced, if the spectra are normalized at the first $1 \mathrm{sC}_{1,2} 1 \pi^{*}$ transition. Moreover, at normal incidence the gas phase and the collector plate spectra were almost equal. Since the dominant gas-phase contribution to the collector signal was constant, which is 
obviously also angular independent, the enhanced transitions must have surface origin. The other important observation in Fig. 9 is that the $1 \pi^{*}$ transition corresponding to the " $\mathrm{C}=\mathrm{O}$ part" of the molecule is clearly increased compared to the " $\mathrm{C}=\mathrm{C}$ part", relative to gas phase. The comparison of gas phase acrolein to the collector signal of $7.5 \mathrm{Ag} / \mathrm{SiO}_{2}-\mathrm{IW}$ and $\mathrm{Ag}$ foil (Fig. 10) demonstrates this effect more clearly.

\section{Discussion}

By using materials with increasing complexity from single crystals to disperse Ag/support catalysts, a significant material dependence has been found in the gas phase hydrogenation of acrolein over silver catalysts. Flat, polycrystalline substrates like sputtered or electrochemical deposited silver mainly yield propionaldehyde, whereas the amount of allyl alcohol formed is up to $42 \%$, when using nano-crystalline, silica supported Ag. However, also in this case, differences between different catalysts exist: the smaller the particles, the higher the amount of allyl alcohol formed. The formation of allyl alcohol therefore seems to be bound to active sites most abundant on small particles. Probably atoms at kinks and edges favour the formation of $\mathrm{AyOH}$, consistent with the findings of Fuji et al. [6], that electropositive sites like kinks and edges favour the coordination (and therefore the activation) of the $\mathrm{C}=\mathrm{O}$-double bond. It has been shown for the case of gold catalyst, that decoration of the planes of the cuboctahedral gold with (inactive) indium while leaving the edges and corners free leads to an enhanced selectivity to $\mathrm{AyOH}$ in the case of acrolein hydrogenation, clearly indicating that $\mathrm{AyOH}$ formation in that case is bound to the presence of edges and corners [27].

In situ-XAS is a powerful tool to gain insight into the orientation of surface species on well-defined surfaces in gaseous ambient. In the XAS measurements, the dipole selection rule tells us that the resonance intensity corresponding to a molecular orbital final state is larger if the $\boldsymbol{E}$ vector points in the direction of that molecular orbital. We have shown that relative to the normal incidence spectrum some of the $\mathrm{C}-\mathrm{K}$ edge transitions were enhanced at grazing incidence. The sketch on Figure 11 illustrates how $\pi$ and $\sigma$ orbitals on the surface should be aligned to end up with the corresponding angular dependence. The axes of $\pi$-like functional groups $(\mathrm{C}=\mathrm{O})$ thus lie parallel to the surface (the $\pi$ orbital itself is perpendicular) and $\sigma^{*}$ orbitals $(\mathrm{C}-\mathrm{H})$ orientate preferentially perpendicular. Consequently, the surface species on $\operatorname{Ag}(111)$ is in the lying-down orientation in this pressure region $\left(0.01 \mathrm{mbar} \mathrm{AC}+\sim 7.5 \mathrm{mbar}_{2}\right)$, which is similar to the results obtained on $\mathrm{Pt}(111)$ at low temperature $(\sim 100 \mathrm{~K})$ in UHV [23].

As a result of the enhanced " $\mathrm{C}=\mathrm{O}$ " to " $\mathrm{C}=\mathrm{C}$ " transition (Fig. 9 and 10), " $\mathrm{C}=\mathrm{O}$ " is accumulated on the surface, or what is more in line with the catalytic data, $\mathrm{C}=\mathrm{C}$ double bonds are almost not present on the surface. Subtracting the normal incidence spectrum of $\operatorname{Ag}(111)$ from the grazing

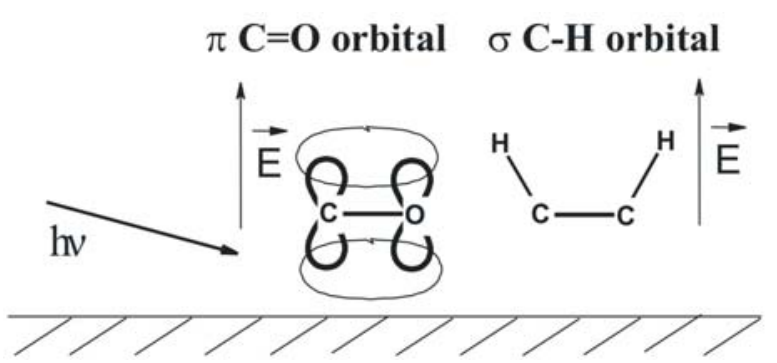

Figure 11: Schematic representation of the orientation of $\pi$ $\mathrm{C}=\mathrm{O}$ and $\sigma(\mathrm{C}-\mathrm{H})$ orbitals on the surface. The enhancement of the corresponding XAS features at grazing incidence (dipole selection rule) is pointed out.

incidence spectrum (shown in Fig. 9) we end up with the noisy signal shown at the bottom of the same figure. This signal is now completely surface related and orientation enhanced by the selection rule. Although the spectrum is very noisy, the similarity to the gas-phase propionaldehyde signal (after similar background subtraction) is obvious. Consequently, the surface signal measured on $\operatorname{Ag}(111)$ during acrolein hydrogenation consist mainly of a propionaldehyde-like surface entity orientated in the "lying-down" manner to the surface. This species can be considered as a partly hydrogenated acrolein that after further hydrogen insertion desorbs as propionaldehyde. In this way, the surface signal is completely in accordance with the detected gas-phase composition.

When using $\operatorname{Ag}(100)$ at normal incidence, the collector plate signal (not shown) appears similar to the $\mathrm{Ag}$ foil and $7.5 \mathrm{Ag} / \mathrm{SiO}_{2}$-IW spectra in Fig. 10. Moreover, there is no further enhancement (as in Fig. 9) when changing the incidence angle to grazing incidence. This suggests that the orientation of the hydrogenated surface species is not exclusively parallel to the surface on $\operatorname{Ag}(100)$. However, the similarity between these spectra and the one taken on the $\mathrm{Ag}(111)$ crystal at grazing incidence indicates, that also on these samples $\left(\mathrm{Ag}(100)\right.$, foil and $\left.\mathrm{Ag} / \mathrm{SiO}_{2}\right)$ a partially hydrogenated, propionaldehyde-like species is present at the surface. Obviously, no conclusion can be drawn on the orientation of this species at the surface of $\mathrm{Ag}$ foil or $7.5 \mathrm{Ag} / \mathrm{SiO}_{2}$-IW catalyst since on these samples no angular dependent measurements are possible due to the nature of the sample.

These in situ-XAS measurements were carried out at $7.5 \mathrm{mbar}$, therefore in the pressure region where no allyl alcohol production was observed. Although the XAS measurements were influenced/enhanced by beam-induced processes, qualitatively the reaction proceeds in the same direction (PA formation) as shown in the pure catalytic tests. Therefore, we believe, the propionaldehyde-like surface intermediate is characteristic for the low-pressure part of the selectivity plot in Fig. 4.

From the presented results it seems reasonable, that the adsorption geometry of acrolein at silver surfaces is dependent upon a) the presence of edge and kink atoms and b) the applied operation conditions (partial pressure) and 
this adsorption geometry influences the selectivity obtained in acrolein hydrogenation. At low pressures, a propionaldehyde-like species has been found at the surface of various materials, indicating a strong interaction of the $\mathrm{C}=\mathrm{C}$-bond with the catalyst surface. This interaction seems to be dominant even for the flat orientation of the partially hydrogenated acrolein that was found at least for the $\operatorname{Ag}(111)$ surface. In the intermediate pressure region, a critical minimum reaction pressure of $\sim 100$ mbar was observed to produce allyl alcohol. Although not shown and discussed in this paper, it should be noted that in the 100-1000 mbar total pressure region the pressure dependence displayed in Fig. 4 originates also from the partial pressure dependence on both reactants as was reported previously [5] for the high-pressure part. At 100 mbar, the partial pressures were $\sim 5$ and $\sim 95$ mbar, acrolein and hydrogen respectively. In an additional measurement using a 10 -to-40 mbar mixture (thus 50 mbar total pressure), we were able to detect small amounts of $\mathrm{AyOH}$. Therefore it seems that the surface coverage of both reactants plays an important role influencing the adsorption geometry. At high pressure, the selectivity approaches $50 \%$, which could be seen as a statistical hydrogenation of either the $\mathrm{C}=\mathrm{O}$ or the $\mathrm{C}=\mathrm{C}$ double bond. Considering an "overcrowded" surface at high pressures, the size of an empty active site should be minimal. The most reasonable adsorption geometry for such a scenario would be an edge-on perpendicular orientation via either double bond. Assuming that the sticking probabilities of both double bonds are very similar on an evolving unstable empty site and that through this edge-on orientation hydrogenation can proceed, the selectivities would approach the nearly observed fifty-fifty case. However, as mentioned above, pressure and materials gap cannot be separated from each other. It is possible that the sticking probability of both double bonds depends on the material, leading to different pressure dependencies on different materials.

Pressure dependent adsorption geometries have been reported for AC adsorption, however, at Pt single crystals but not on silver: reflection-absorption infrared spectroscopy (RAIRS) experiments with the acrolein/Pt(111) system indicated a totally flat bonding via the carbonyl moiety, the $\mathrm{C}=\mathrm{O}$ bond must be oriented parallel [21]. Above a coverage of $7.0 \mathrm{~L}$, condensation of acrolein on the surface in a multilayer was observed. From the results of semiempirical extended Hückel calculations it was concluded that increasing the coverage favours the di- $\sigma_{\mathrm{CO}}$ coordination, which can yield a denser packing and improve the selectivity to the unsaturated alcohol [28]. A combined approach of DFT calculations, vibrational spectra simulations with high-resolution electron energy loss spectroscopy (HREELS) of acrolein adsorption over Pt(111) shows that the structure of strongly bonded species is coverage dependent changing from a flat coordination by both the $\mathrm{C}=\mathrm{C}$ and the $\mathrm{C}=\mathrm{O}$ group at low coverage toward a high coverage $\eta_{2}$-cis and $\eta_{2}$-trans form on the surface [29]. These studies suggest that the pressure dependence of in- tramolecular selectivity is dictated by different adsorption orientations and/or different rate-controlling processes on the catalyst surface. In this context it is interesting to note that the overall activation energy is independent of the pressure, at least in the high-pressure range, and of material, indicating that the pressure dependent acrolein adsorption itself is most likely not the rate-determining step. The in situ- XAS results strongly suggest the detection of a partly hydrogenated product at the catalyst surface. This could indicate that addition of the second hydrogen - at least at low pressure - is slow and rate determining, whereas the adsorption and addition of the first hydrogen are fast. This might be consistent with a recent study of Khanra et al. [11]. The authors identified the desorption of products as steps with the highest activation barrier in acrolein hydrogenation over $\operatorname{Ag}(111)$. Considering that the second hydrogen addition leads directly to desorption, our experimental results seem to strengthen the calculations of Khanra et al. However, in order to reach a more detailed understanding and to extract a micro-kinetic model, comprehensive experiments on elementary steps as well as theoretical investigations by means of DFT calculation have to be performed, which are currently being carried out.

Summarising, small silver particles and high pressures favour the formation of allyl alcohol in the gas phase hydrogenation of acrolein, which can be explained by the adsorption geometry of acrolein. A critical minimum pressure barrier was identified that is essential to the formation of allyl alcohol. It is the very first time that reaction intermediates on the catalyst surface were observed using in situ-XAS. A partly hydrogenated propionaldehyde-like surface species was found with flat orientation (at 7.5 mbar).

\section{Acknowledgements}

D. $\mathrm{Su}$ is gratefully acknowledged for the HR-TEM pictures. This research is funded by the DFG (German research foundation) within the priority program 1091 "Brückenschläge zwischen realen und idealen Systemen in der heterogenen Katalyse". A. Wootsch thanks for Grant Bólyai. In addition, we thank the BESSY staff for their continual support during the XAS measurements. 


\section{References}

[1] Q. Zhang, J. Li, X. Liu, Q. Zhu, Appl. Catal. A. 197 (2000) 221.

[2] E. A. Sales, B. Benhamida, V. Caizergues, J.-P. Lagier, F. Fievet, F. B. Verduraz, Appl. Catal. A 172 (1998) 273.

[3] I. Sárkány, Zs. Révay, Appl. Cat. A. 243 (2003) 347.

[4] W. Grünert, A. Brückner, H. Hofmeister, P. Claus, J. Phys. Chem. B 108 (2004) 5709.

[5] M. Bron, E. Kondratenko, A. Trunschke, P. Claus, Z. Phys. Chem. 218 (2004) 51.

[6] S. Fuji, N. Osaka, M. Akita, K. Itoh, J. Phys. Chem. 99 (1995) 6994.

[7] J.L. Solomon, R.J. Madix, J. Stöhr, J. Chem. Phys. 89 (1988) 5316.

[8] J.L. Solomon, R.J. Madix, J. Phys. Chem. 91 (1987) 6241.

[9] K.R. Christmann, in: Z. Paál, P.G. Menon (Eds.), Hydrogen Effects in Catalysis, Marcel Dekker, Inc., New York, Basel, Vol. 31, 1988, p. 12.

[10] R.N. Carter, A. Brad Anton, G. Apai, Surf. Sci. 290 (1993) 319.

[11] B.C. Khanra, Y. Jugnet, J.C. Bertolini, J. Molecular Catal. A 208 (2004) 167.

[12] M. Lucas, P. Claus, Chem.-Ing.-Tech. 67 (1995) 773.

[13] Z. Paál, H. Groeneweg, H. Zimmer, Catal. Today 5 (1989) 199.

[14] K. Noack, H. Zbinden, R. Schlögl, Catal. Lett. 4 (1990) 145.

[15] A. Knop-Gericke, M. Hävecker, T. Neisius, T. SchedelNiedrig, Nucl. Instrum. Methods A 406 (1998) 311.
[16] A. Knop-Gericke, M. Hävecker, T. Schedel-Niedrig, R. Schlögl, Catal. Lett. 66 (2000) 215.

[17] L. H. Tjeng, M.B.J. Meinders, J. van Elp, J. Ghijsen, G. Sawatzsky, R.L. Johnson, Phys. Rev. 8B 41 (1990) 3190.

[18] D. Wagner, Faraday Discuss. Chem. Soc. 160 (1975) 291.

[19] M. Bron, D. Teschner, A. Knop-Gericke, A. Scheybal, B. Steinhauer, M. Hävecker, R. Födisch, D. Hönicke, R. Schlögl, P. Claus, Catal. Commun. 6 (2005) 371.

[20] B. Steinhauer, D. Teschner, A. Knop-Gericke, M. Bron, R. Schlögl, P. Claus, in preparation.

[21] J. Carlos de Jésus, F. Zarea, Surf. Sci. 430 (1999) 99.

[22] D. Duflot, J.-P. Flament, I. C. Walker, J. Heinesch, M.-J. Hubin-Franskin, J. Chem Phys. 118 (2003) 1137.

[23] F. Bournel, C. Laffon, Ph. Parent, G. Tourillon, Surf. Sci. 350 (1996) 60.

[24] M. F. Arendt, P. W. Browning, L. J. Butler, J. Chem. Phys. 103 (1995) 5877.

[25] P. Hitchcook, I. Ishii, J. Electron Spectrosc. Relat. Phenom. 42 (1987) 11.

[26] G. Distefano, M. Guerra, D. Jones, A. Modelli, Chem. Phys. 68 (1982) 383.

[27] B. Mohr, H. Hofmeister, J. Radnik, P. Claus, J. Am. Chem. Soc. 125 (2003) 1905.

[28] F. Delbecq, P. Sautet, J. Catal. 152 (1995) 217.

[29] D. Loffreda, Y. Jugnet, F. Delbecq, J. C. Bertolini, P. Sautet, J. Phys. Chem. B 2004, 108, 9085. 